\title{
Review of the Bank of Russia - NES Workshop 'Main Challenges in Banking: Risks, Liquidity, Pricing, and Digital Currencies'1
}

\author{
Ivan Khotulev, Bank of Russia \\ khotulevim@mail.cbr.ru
}

In October 2021, the Bank of Russia and the New Economic School (NES) hosted a joint international online workshop titled 'Main Challenges in Banking: Risks, Liquidity, Pricing, and Digital Currencies'. Six papers were presented. They addressed various issues in banking which are currently of paramount importance to central bankers, market participants, and academics: the connections between systemic risk and the real economy, the digitalisation of finance and information asymmetries, credit spreads and monetary policy, the improvement of information flows and outcomes in credit markets, the introduction of central bank digital currencies, and bank intermediation.

Keywords: systemic risk, macroprudential policy, customer data, central bank digital currency

JEL Codes: D82, E44, G21, E50
Citation: Khotulev, I. (2021). Review of the Bank of Russia - NES Workshop 'Main Challenges in Banking: Risks, Liquidity, Pricing, and Digital Currencies'. Russian Journal of Money and Finance, 80(4), pp. 124-136.

doi: $10.31477 /$ rjmf.202104.124

\section{Introduction}

In October 2021, the Bank of Russia and the New Economic School (NES) hosted a joint international online workshop titled 'Main Challenges in Banking: Risks, Liquidity, Pricing, and Digital Currencies'. As was noted by Alexander Morozov, director of the Research and Forecasting Department of the Bank of Russia, most of the presenters were from central banks. This indicates that central banks all over the world are facing common challenges as they navigate the changing landscape of banking and banking regulation. Six papers were presented. They

\footnotetext{
${ }^{1}$ The views expressed in this paper are solely those of the author and do not necessarily reflect the official position of the Bank of Russia. The Bank of Russia assumes no responsibility for the contents of the paper.
} 
addressed various issues in banking which are currently of paramount importance to central bankers, market participants, and academics: the connections between systemic risk and the real economy, the digitalisation of finance and information asymmetries, credit spreads and monetary policy, the improvement of information flows and outcomes in credit markets, the introduction of central bank digital currencies, and bank intermediation.

This review paper is organised as follows: Section 2 discusses the research objectives of the papers presented at the workshop, Section 3 lists the data sources used by the researchers, Section 4 outlines their methods, Section 5 presents the results of their research, and Section 6 concludes.

\section{Research objectives}

In her opening remarks, First Deputy Governor of the Bank of Russia Ksenia Yudaeva reminded the audience that the last 10-15 years have seen tremendous changes in the banking sector. It is, therefore, important to reflect on the trends that will shape the future of banking: the rise of fintech and digital assets, changes in regulation and data governance, possible introduction of central bank digital currencies. These issues are of great importance to Russia as Russia's financial system is based on bank credit, rather than on stock markets.

The papers presented at the workshop had the objective of studying these themes. Johannes Poeschl of Danmarks Nationalbank presented his joint paper with Jakob Mikkelsen, also from Danmarks Nationalbank, on the relationship between the risk of bank panic and macroeconomic uncertainty (Mikkelsen and Poeschl, 2020). The objective of their research is to shed light on the relationship between systemic risk and macroeconomic uncertainty, because these are complicated concepts and the relationship between them is not clear.

Alexey Ponomarenko of the Bank of Russia presented his joint research with Elena Deryugina and Andrey Sinyakov, both from the Bank of Russia, on the connection between the structures of the deposit and credit markets in the digital economy in the presence of information asymmetry (Deryugina et al., 2021). To date, there has been very little literature about how banks' market power in the funding market affects outcomes in the lending market. When a bank observes its clients' deposits and transactions, it gains an information advantage concerning its clients' creditworthiness. When big banks dominate the deposit market, they have an information advantage over smaller players, and opportunities for strategic pricing behaviour arise. The authors study how big players' information advantage in the deposit and transaction markets affects outcomes in the lending market.

At the workshop, Ksenia Yudaeva announced the winner of the Second Economic Research Competition held by the Bank of Russia and the Russian Journal of Money and Finance. This year's winner, Filipp Prokopev, previously 
in the Joint HSE-NES Undergraduate Program in Economics and currently at the University of Michigan, presented his paper on the balance sheet channel of monetary policy (Prokopev, 2021). ${ }^{2}$ The objective of his research is to analyse the relationship between the credit spreads of Russian bond issuers and monetary policy shocks. On one hand, according to the theory of demand-side financial imperfections, the higher is the net worth of a firm, the lower its external finance premium must be in the presence of financial frictions. On the other hand, the theory of the balance sheet channel of monetary policy suggests that monetary shocks may affect the net worth of a firm through debt outflows. Together, these ideas predict that the external finance premium of more indebted companies must be more sensitive to monetary policy shocks. The purpose of the paper is to test this relationship empirically.

Ricardo Schechtman of the Central Bank of Brazil presented two papers, joint with his colleagues from the Central Bank of Brazil, FECAP (Fundação Escola de Comércio Álvares Penteado), and Insper (Bonomo et al., 2020; Ornelas et al., 2021). The objective of these papers is to study whether the sharing of positive credit bureau information improves outcomes for borrowers. The authors use changes in regulations that improve the information available to financial institutions on borrowers with good credit repayment histories as quasi-natural experiments to investigate the causal effect of a reduction of informational asymmetries on credit outcomes.

The Credit Information System (abbreviated SCR in Portuguese) is managed by the Central Bank of Brazil. Lenders (banks and non-banks) report detailed monthly information on their credit relationships with their clients, including overall debt exposure, term structure of scheduled repayments, and amounts past due. Since 1997, financial institutions have been required to submit individualised loan information for each borrower with total liabilities greater than or equal to 5,000 Brazilian reals (BRL). This amount was later reduced to $1,000 \mathrm{BRL}$ in 2012 and, as of June 2016, this limit was further reduced to $200 \mathrm{BRL}$, which increased the number of individuals in the SCR from 64 million to 105 million, encompassing $99 \%$ of all credit transactions.

There are also private credit bureaus in Brazil. They cover almost the same proportion of borrowers as the SCR, but, until 2019, they mainly reported the socio-economic characteristics of borrowers and negative information about them, such as late payments and default amounts. In 2019, they were legally authorised to sell the credit risk scores of individuals based on a wider range of data, including positive information, such as overall debt exposure and the term structure of scheduled repayments. The purpose of the first paper (Bonomo et al., 2020 ) is to evaluate the effects of the public credit registry's lowering of the reporting threshold by in 2016. The purpose of the second (Ornelas et al., 2021)

2 The paper is published in the current issue of the Russian Journal of Money and Finance, pp. 3-30. 
is to evaluate the effects of the introduction of the new credit scores by private credit bureaus in 2019.

Yu Zhu of the Bank of Canada presented his paper studying the impact of a central bank digital currency (CBDC) on the intermediation of private banks (Chiu et al., 2021). A CBDC is a digital form of central bank money that can be used for general payments. Many central banks are currently considering the issuance of CBDCs. However, one concern is that CBDCs may cause bank disintermediation. They may compete with bank deposits as a payment instrument. Banks would be forced to raise deposit rates and, therefore, also raise lending rates and reduce lending (Bank for International Settlements, 2018, p. 16). The purpose of this paper is to study theoretically the effects of the introduction of a deposit-like interest-bearing CBDC on bank intermediation.

\section{Data}

To motivate their study, Mikkelsen and Poeschl (2020) show the evolution of several uncertainty indices in the United States during the global financial crisis of 2008 (Figure 1). Here, the TED spread (Figure 1a) is the 3-month LIBOR minus the 3-month US treasury rate and is used as a measure of systemic risk in the financial system. VIX (Figure 1b) is the Volatility Index of the Chicago Board Options Exchange (CBOE), a popular measure of the stock market's expectation of volatility based on S\&P 500 index options. It is used as a measure of stock market uncertainty. The Jurado et al. (2015) index uses a data-rich environment to provide estimates of time-varying macroeconomic uncertainty (Figure 1c). It is highly correlated with real economic activity, and so it is used as a measure of real macroeconomic uncertainty. To motivate a connection with the real economy, the authors also use aggregate macroeconomic and financial time series: credit spreads, the aggregate net worth of banks, real GDP, real consumption, and real investment.

Since the main contribution of Deryugina et al. (2021) is theoretical in nature, the authors calibrate their model's parameters and simulate artificial data. They randomly set the interest rates that big and small banks begin with, and then simulate the banks' optimal strategies until their interest rates settle into equilibrium.

Prokopev (2021) takes bond data for the entire population of Russian issuers from the Cbonds database, and financial filings from the Cbonds and SPARK databases. He uses the following variables for bonds and financial filings: spreads, net worth, total assets, two alternative definitions of leverage (total assets over net worth and debt over net worth), cash, bond times to maturity, coupon rates, duration, and amount outstanding. Monetary shocks are calculated as the difference between the policy rates announced and the consensus policy rate forecasts from Bloomberg surveys of professional macro-forecasters. The 
identifying assumption here is that analysts have access to the same information on current economic conditions as a central bank and assess that information efficiently. The author presents evidence that this variable can be used as a measure of monetary policy shocks. Standard statistical tests suggest that this measure of monetary policy surprises has near-zero mean and no serial correlation.

Figure 1. Measures of systemic risk (TED spread)

and aggregate uncertainty (VIX and Jurado et al. (2015) uncertainty index)

a) TED spread

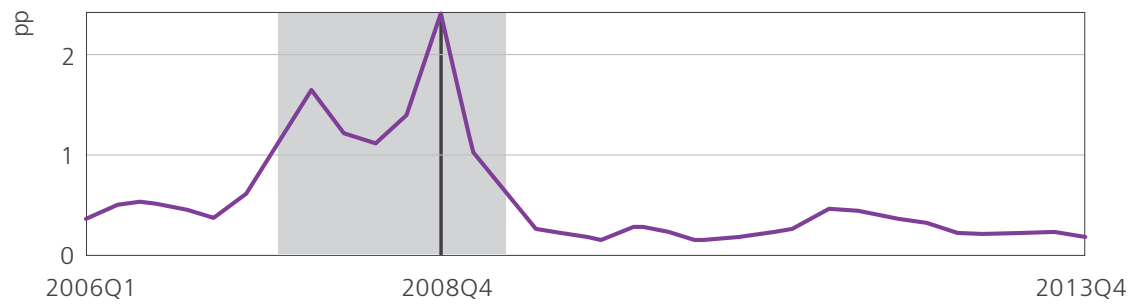

b) VIX

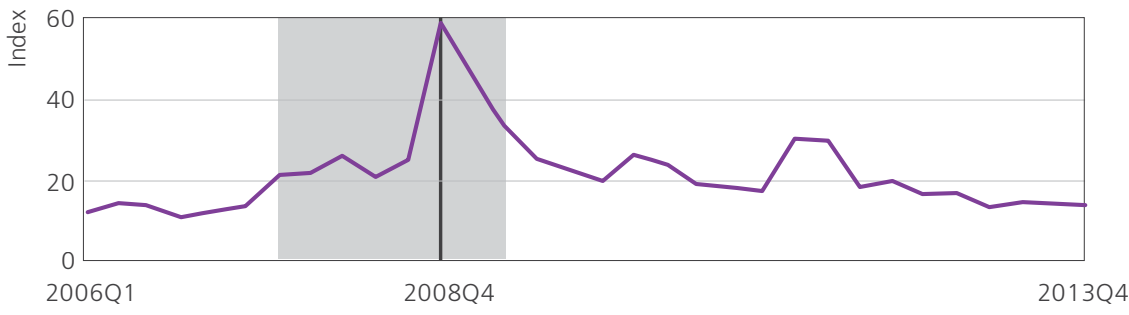

c) Jurado et al. (2015) uncertainty index

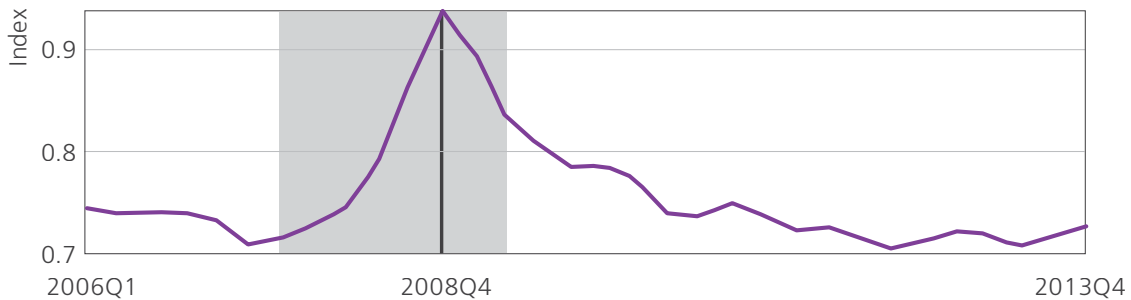

Note: Shaded area indicate recessions dates NBER.

Source: Mikkelsen and Poeschl (2020, p. 5)

In the paper by Bonomo et al. (2020), the data come from the SCR. The sample ranges from January 2016 until January 2017. The variables are divided into three categories: loan outcomes, borrower characteristics, and financial characteristics. Loan outcomes include the original amount of a loan (in BRL), the spread (the lending rate minus the deposit rate), the maturity, and one of five loan risk categories. Borrower characteristics include monthly income, age, and gender. Financial characteristics include an indicator for private banks, an indicator for 
small- and medium-sized banks, indebtedness (total credit to annual income), debt service ratio (principal plus interest), and the number of banks in the municipality. Ornelas et al. (2021) use the credit scores calculated by private credit bureaus, in addition to the loan-level information from the public SCR credit registry. Here, the sample period is August 2019 as a placebo period before the change, and from August to December 2020 as the period after the change.

In order to quantify the effects of a deposit-like CBDC, Chiu et al. (2021) calibrate their model to the US economy. They obtain time series for inflation, 3-month T-bill rates, prime rates, GDP, and total commercial loans. They obtain the parameters of payment acceptance from the Survey of Consumer Payment Choice (SCPC) and the Diary of Consumer Payment Choice (DCPC). The SCPC contains information on the fraction of online transactions, and the DCPC contains information on the perceived fraction of point-of-sale transactions that do not accept cash or debit/credit cards. The authors compute banks' interest rates and operational costs from the Federal Financial Institutions Examination Council's call reports. They divide the interest expenses on transaction accounts by the total transaction deposits to obtain the rates on transaction deposits for each bank in each quarter. To obtain banklevel loan rates, they divide the interest income from loans by the quantity of loans. They infer the operational cost per dollar of assets from the cost per dollar of total deposits, assuming that the relationship between total assets and total deposits is stable.

\section{Methods}

Although various measures of risk and uncertainty are correlated, the exact relationship between them is far from clear. To uncover this relationship, Mikkelsen and Poeschl (2020) construct a dynamic stochastic general equilibrium (DSGE) model with endogenous financial crises and uncertainty shocks. There are four main types of agents in their model economy: households, banks, producers of final goods, and producers of capital goods. Households consume, work, own banks, and can make loans to banks or firms, but they face a cost when lending to firms. Banks borrow from households, lend to firms, and reinvest their net worth. Importantly, banks' borrowing is limited by a moral hazard problem, and they do not issue equity. It is also important to note that producers of final goods produce output using capital and labour, subject to capital quality shocks with time-varying volatility. They finance capital with loans from households and banks. Finally, producers of capital goods transform final goods into capital goods, subject to a quadratic investment adjustment cost.

If a bank does not have enough funds to repay its liabilities and cannot borrow or raise equity, it must default. If a representative bank operates normally, its assets are valued at normal prices. If it does not, its assets are valued at fire-sale 
prices, and a financial crisis ensues. Since the future net worth of banks depends on whether their assets are valued at normal or fire-sale prices, the probability of financial crisis endogenously measures time-varying systemic risk.

To answer their research question, Deryugina et al. (2021) construct a gametheoretic model with many identical small banks and one large bank in the market. The banks' clients are households, which use bank services to make payments and to borrow money. The large bank services a large share of the households and the small banks divide the remaining share equally. The households are divided into the categories of 'good' borrowers, who repay their loans with a probability of one, and 'bad' borrowers, who default at a certain probability. Each bank can identify borrower type only for those households who use its transaction services, and so, from a bank's perspective, potential borrowers are divided into the 'good', the 'bad', and the 'unknown'.

The banks compete by setting loan rates for each of the three types of borrowers. Every bank's rates are known to all clients who decide to take out loans, as well as to the other banks. A full lending cycle takes place in every period; that is, the banks offer rates, the borrowers choose their banks, take out and repay loans, and the banks make their profit. The game repeats in the next period. There is no process of learning from the previous period through 'learning by lending'. By symmetry, all of the small banks offer the same rates, while the big bank's rates may differ.

The authors consider two solution concepts. The first is a Nash equilibrium in which the big bank and the small banks set their lending rates simultaneously. The other solution concept is conceptually similar to a Stackelberg equilibrium. In this case, the 'leader' does not pursue the goal of increasing its profits right away, but chooses its rates in such a way as to force the 'follower' to optimise its rates too. Having the opportunity to predict the behaviour of the 'follower', the 'leader' tries in its step to select its rates such that, after the 'follower' responds, it can make a profit greater than in the standard Nash equilibrium.

Prokopev (2021) uses two empirical specifications. The first is a distributed lag model, that is, a regression equation predicting current values of a dependent variable based on both the current and the lagged values of the explanatory variables (Equation 1).

$$
\begin{array}{r}
\text { Spread }_{i t}=\beta_{0}+\sum_{p=0}^{11} \beta_{p} \text { Leverage }_{i t-12} \text { MonetaryShock }_{t-p} \\
+X_{i t-12}+\alpha_{t}+\alpha_{i}+\epsilon_{i t}
\end{array}
$$

Here, Spread ${ }_{i t}$ is the spread on a firm's bonds; Leverage ${ }_{i t-12}$ is the 12 th monthly lag of leverage; MonetaryShock ${ }_{t-p}$ is the $p$ th lag of a monetary policy shock; $\alpha_{t}$ and $\alpha_{i}$ are the time- and firm-fixed effects. $X_{i t-12}$ is the set of the 12th lags of the controls: net worth, size, leverage, and cash. The standard errors $\epsilon_{i t}$ are 
clustered at the firm level. In addition to this basic specification, other specifications also include the cross terms of the $p$ th lag of a monetary policy shock with the 12 th lags of size, net worth, and cash.

The other empirical specification is a local projection, that is, a regression of the dependent variable on the past values of the independent variables in order to estimate the autoregressive coefficients directly at each $h$-step ahead (Equation 2).

$$
\begin{array}{r}
\text { Spread }_{i, t+h}=\beta_{0}+\alpha_{t}^{h}+\alpha_{i}^{h}+\beta_{1}^{h} \text { Leverage }_{i, t-1} \text { MonetaryShock }_{t} \\
+X_{i, t-1}+\epsilon_{i, t+h}
\end{array}
$$

Bonomo et al. (2020) estimate a difference-in-differences (DID) panel regression to estimate the effects of the sharing of positive credit information. They define the treated group as individuals that had maximum total liabilities to any financial institution between $500 \mathrm{BRL}$ and 1,000 BRL as of June 2016 and whose information had not been disclosed in the SCR before the change in the threshold. For their control, they use the group of borrowers that had maximum total liabilities per bank between 1,000 BRL and 1,500 BRL and, consequently, whose information had been reported to the SCR before June 2016. The identifying assumption is that, absent the threshold change, the outcomes of the treated and non-treated individuals would have followed parallel trajectories.

Ornelas et al. (2021) estimate a panel regression with fixed effects. To identify causality, they exploit the fact that borrowers' new scores were not all available for sale simultaneously. The bureaus register individuals and proceed to compute the new scores. This results in lenders receiving new scores for some individuals and old scores for others. Additionally, the process within the credit bureaus that resulted in some individuals having their new scores available earlier than others seems quite random. Therefore, the availability of the new scores to lenders works as a quasi-natural experiment.

Chiu et al. (2021) develop a micro-founded general equilibrium model of payments in order to study the impact of a CBDC on the intermediation of private banks. In their model, banks create deposits and make loans. Deposits are inside money used for transactions. Banks have market power in the deposit market. There are four types of private agent: households, divided into buyers and sellers, entrepreneurs, and bankers, who own commercial banks. There is also a consolidated government consisting of a central bank and a fiscal authority.

\section{Research results}

In the paper by Mikkelsen and Poeschl (2020), since the probability of financial crisis affects the expectations for future asset prices, macroeconomic 
uncertainty, which is defined as the standard deviation of the endogenous variables, is affected by systemic risk. The first result of the paper is that, when the probability of financial crisis is low, higher systemic risk increases macroeconomic uncertainty.

On the other hand, macroeconomic uncertainty affects the economy through three channels. Through the channel of households' precautionary savings, higher uncertainty lowers the deposit rate, which leads to a lower probability of financial crisis. Through the credit spread channel, higher uncertainty leads to higher risky returns, which also lowers the probability of financial crisis. Finally, through the bank leverage channel, higher uncertainty leads to lower bank leverage, which also reduces the probability of financial crisis. Although all three channels are contractionary, they nevertheless reduce the probability of a financial crisis.

The authors also consider the effects of macroprudential policy, which they model as a capital requirement with a countercyclical buffer (CCyB). Because of the feedback loop between systemic risk and macroeconomic uncertainty, the $\mathrm{C} C \mathrm{BB}$ reduces systemic risk and thereby also reduces macroeconomic uncertainty.

Thus, Mikkelsen and Poeschl (2020) make three contributions and uncover a novel feedback loop between systemic risk and macroeconomic uncertainty. First, they show a finance-to-macro link, as the possibility of financial crises leads to endogenously time-varying macroeconomic uncertainty. Second, the authors demonstrate a macro-to-finance link, as higher macroeconomic uncertainty reduces the likelihood of a financial crisis. Third, they show a novel general equilibrium benefit of macroprudential regulation, as a countercyclical capital buffer reduces systemic risk and thereby also reduces macroeconomic uncertainty.

Deryugina et al. (2021) draw the following conclusions. First, a dominant position in the payment and deposit market provides the basis for strategic behaviour in the credit market and predetermines dominance in the lending market. A large bank with an information advantage may select good borrowers and push other borrowers out to other banks as unknown borrowers, thereby worsening the distribution of borrowers available to the rest of the credit market. Second, loan pricing plays an important role in the implementation of a dominant bank's strategy. Known good borrowers get lower rates, and known bad borrowers get higher rates. At the same time, the interest rates offered to unknown borrowers increase. The strategic behaviour of a large player leads to greater differentiation of rates in the market. Third, higher rates for unknown borrowers and for bad borrowers known to banks result in a decrease in the demand in these categories, decreasing the inclusiveness of the lending market. Fourth, the weighted average risk on the balance sheet of the banking sector is reduced by the small banks' narrowing of their customer base. For the large bank, it is strategically more profitable to accept the additional risk of an increase in the number of borrowers, since it is offset by an increase in profits. 
Discussant Yu Zhu noted in his remarks (Zhu, 2021) that, although the research by Deryugina et al. (2021) is very timely and relevant to policy, the paper would benefit from more analytic results and explanation. More counterfactuals and policy analysis could be done. For example, it would be interesting to know whether regulations forcing banks to share information would improve welfare.

To the best of the author's knowledge, Prokopev's paper (2021) is one of the first to study credit spreads at the microlevel in an emerging economy. The results of the estimation suggest that there is no statistically significant heterogeneity in the reaction of Russian bond issuers' external finance premium to monetary shocks. These results suggest that the premium for external financing reacts to monetary shocks in the same way regardless of financial structure (leverage).

Bonomo et al. (2020) focus on the effect of the change in the credit reporting threshold on financial variables. After the change, they find a decrease in spreads of approximately $33.5 \mathrm{pp}$ (of a sample average of $304 \%$ ) $^{3}$ and no significant change in the amount of new credit originated, in maturity, or in the risk ratings given by banks to new borrowers. They also investigate if the sharing of positive information may have heterogeneous effects depending on the size of the bank. The results indicate that the impact of the change in the information environment matters most for smaller banks. For smaller banks, the loan spread rate decreased by $42 \mathrm{pp}$, and origination increased by $24 \%$.

Ornelas et al. (2021) find an average reduction of $6.9 \%$ in the interest rates on personal loans to new borrowers for whom new scores were available for sale from the private credit bureaus, as compared to new borrowers for whom only old credit scores were available. The effects are stronger in those cases where the new score is much higher than the old score, reaching an average reduction of $12.5 \%$. The authors do not find statistically significant effects on loan interest rates for new borrowers whose new scores are lower than their old scores.

Regarding the results of Bonomo et al. (2020), discussant Sergey Seleznev of the Bank of Russia noted that the quasi-experiment used in the study was not the first change in reporting requirements and that it would, therefore, be interesting to study previous changes for completeness. He also noted that the results of Ornelas et al. (2021) could be contaminated by the ongoing COVID-19 pandemic during the sample period after the change.

Chiu et al. (2021) study a version of the model without a CBDC first. There are two means of payment between buyers and sellers: cash issued by the central bank and deposits issued by commercial banks, which differ in terms of acceptance. The optimality conditions for cash and deposits imply an inverse demand for deposits by buyers. The authors then introduce an interest-bearing CBDC designed to be a perfect substitute for bank deposits. It pays nominal

\footnotetext{
${ }^{3}$ According to Bonomo et al. (2020), Brazil has one of the highest credit spreads in the world, especially for lower income clients who are considered more risky.
} 
interest $i_{e}$ (positive or negative) that implies gross real rate $R_{e}$. For deposit rates below $R_{e}$, households hold only the CBDC, rather than deposits, which changes the shape of the inverse demand for deposits (Figure 2).

Figure 2. Inverse demand for deposits without a CBDC (left panel) and with a CBDC (right panel)
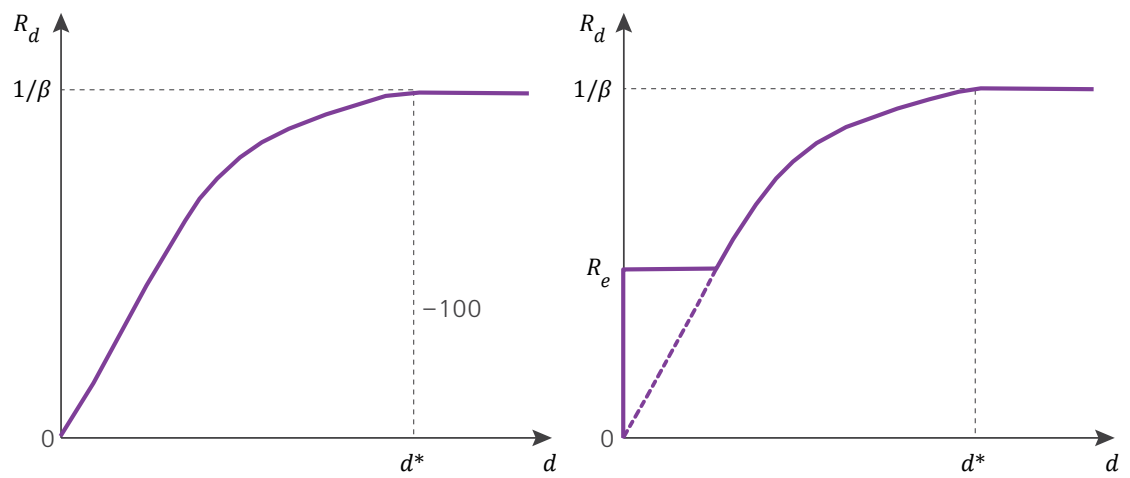

Source: Chiu et al. (2021, p. 12)

Figure 3. Equilibrium in the loan market without a CBDC (left panel), with a CBDC paying medium interest $i_{e}$ (middle panel), and a CBDC paying high interest $i_{e}$ (right panel)
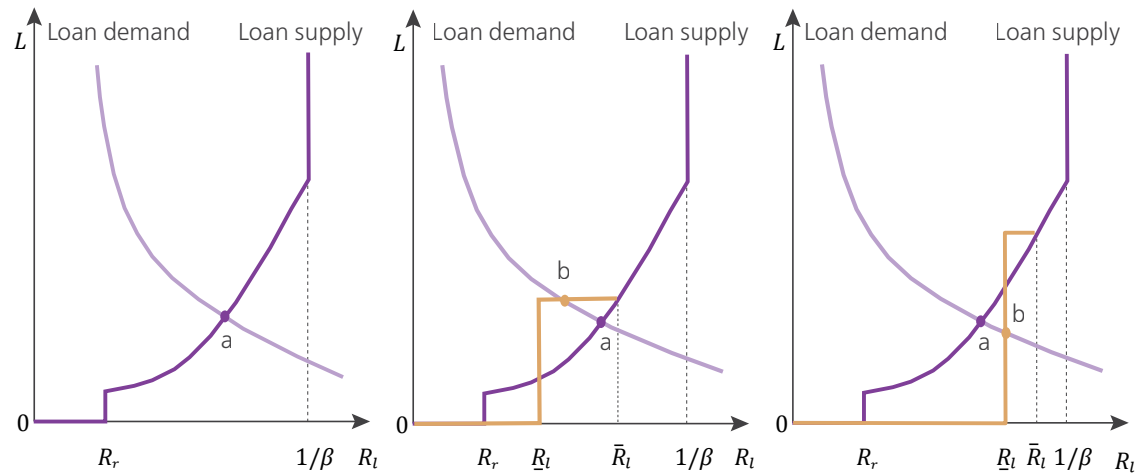

Source: Chiu et al. (2021, p. 18)

Competition in the deposit market by bankers implies an aggregate loan supply. Optimisation by entrepreneurs implies a loan demand function. Under particular technical conditions, a unique symmetric equilibrium exits in the loan market. Because the introduction of a CBDC changes the shape of the inverse demand for deposits, it also changes the shape of the loan supply. The equilibrium amount of lending can either increase or decrease depending on CBDC interest $i_{e}$ (Figure 3). 
The calibration to the US economy suggests that a CBDC promotes bank intermediation when $0.3 \%<i_{e}<1.49 \%$. It also increases output when $0.3 \%<i_{e}<1.26 \%$. The introduction of a CBDC may achieve a maximum increase of $1.96 \%$ in lending and $0.21 \%$ in output. An interest-paying CBDC may encourage banks to raise their interest rates on deposits, which in turn would increase the supply of deposits and lending in the economy. Interestingly, a noninterest-paying CBDC may also have a positive effect, because it would put a zero lower bound on real deposit rates.

In his remarks (Kovbasyuk, 2021), discussant Sergey Kovbasyuk of the NES acknowledged the timeliness and relevance of the paper. However, he noted that the central bank moneys (reserves, cash, and CBDC) in the model are exchanged at par. Since different instruments have different liquidity (usage) premia, they may actually have an equilibrium exchange rate that is not equal to one. Yu $\mathrm{Zhu}$ replied that some researchers believe that a CBDC should exchange at par with other types of central bank money.

\section{Concluding remarks}

In his concluding remarks, Alexander Morozov noted that uncertainty and information asymmetry were the unifying themes of the workshop. Uncertainty and information asymmetry have negative externalities, and, therefore, reducing uncertainty and asymmetry usually improves public welfare.

Mikkelsen and Poeschl (2020) clearly demonstrate this effect, arguing that macroprudential capital buffers reduce uncertainty in the economy by decreasing the probability of a banking crisis. Bonomo et al. (2020) and Ornelas et al. (2021) show that the sharing of information about borrowers helps good borrowers obtain credit on better terms. It also levels the playing field for small banks and increases competition.

The workshop also addressed the issues of technological innovations in banking in the context of uncertainty and information asymmetry. As Chiu et al. (2021) demonstrate in their paper, a properly designed CBDC could expand financial intermediation and aggregate output. Deryugina et al. (2021) analyse the example of a big market player that benefits from new information received through its ecosystem. Although other players and risky borrowers lose, low-risk borrowers are better off.

Prokopev (2021) challenges existing theory of balance sheet channel of monetary policy, finding no evidence that it is predictive for the Russian corporate bond market. It is probably not the theory that is wrong, however, rather that the Russian corporate bond market is far from being perfect with multiple frictions. 


\section{References}

Bank for International Settlements (2018). Central Bank Digital Currencies. CPMI, Markets Committee Papers, N 174.

Bonomo, M., Bruschi, C. and Schechtman, R. (2020). Effects of Sharing Public Positive Credit Information on Personal Loans. Mimeo, Insper and Central Bank of Brazil.

Chiu, J., Davoodalhosseini, M., Jiang, J. H. and Zhu, Y. (2021). Bank Market Power and Central Bank Digital Currency: Theory and Quantitative Assessment. Bank of Canada Staff Working Papers, N 2019-20, Revised Version.

Deryugina, E., Ponomarenko, A. and Sinyakov, A. (2021). Exploring the Conjunction between the Structures of Deposit and Credit Markets in the Digital Economy under Information Asymmetry. Bank of Russia Working Paper Series, N 78.

Jurado, K., Ludvigson, S. C. and Ng, S. (2015). Measuring Uncertainty. American Economic Review, 105(3), pp. 1177-1216. https://www.doi.org/10.1257/aer.20131193

Kovbasyuk, S. (2021). Discussion of 'Bank Market Power and Central Bank Digital Currency: Theory and Quantitative Assessment'. Presented at the Bank of RussiaNES Workshop 'Main Challenges in Banking: Risks, Liquidity, Pricing, and Digital Currencies', October 7, 2021. https://www.cbr.ru/Content/Document/File/128539/ Kovbasyuk\%20(discussion).pdf [accessed on 21 November 2021].

Mikkelsen, J. G. and Poeschl, J. (2020). Banking Panic Risk and Macroeconomic Uncertainty. Danmarks Nationalbank Working Papers, N 149.

Ornelas, J. R., Oliveira, R. F. and Schechtman, R. (2021). Private Credit Bureaus and Positive Information Sharing: Are There Benefits for Borrowers? Mimeo, Central Bank of Brazil and FECAP.

Prokopev, F. (2021). Balance Sheet Channel of Monetary Policy: Evidence from Credit Spreads of Russian Firms. Russian Journal of Money and Finance, 80(4), pp. 3-30. https://doi.org/10.31477/rjmf.202104.03

Zhu, Y. (2021). Disccusion of 'Exploring the Conjunction between the Structures of Deposit and Credit Markets in the Digital Economy under Information Asymmetry'.

Presented at the Bank of Russia - NES Workshop 'Main Challenges in Banking: Risks, Liquidity, Pricing, and Digital Currencies', October 7, 2021. https://www.cbr.ru/Content/Document/File/128542/Yu\%20Zhu\%20(discussion).pdf [accessed on 21 November 2021]. 